\title{
Lentinus (Panus) tigrinus augmentation of a historically contaminated soil: Matrix decontamination and structure and function of the resident bacterial community
}

\author{
E. Federici ${ }^{a}$, M.A. Giubilei ${ }^{b}$, T. Cajthaml $^{\mathrm{c}}$, M. Petruccioli $^{\mathrm{b}}$, A. D’Annibale $^{\mathrm{b}, *}$ \\ a Dipartimento di Biologia Cellulare e Ambientale, University of Perugia, Via del Giochetto 06100 Perugia, Italy

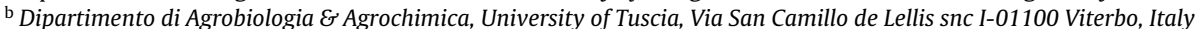 \\ ${ }^{\mathrm{c}}$ Laboratory of Environmental Biotechnology, Institute of Microbiology, Academy of Sciences of the Czech Republic, Vídeňská 1083, CZ-142 20 Prague 4, Czech Republic
}

\section{A R T I C L E I N F O}

\section{Article history:}

Received 10 September 2010

Received in revised form

29 November 2010

Accepted 30 November 2010

Available online 7 December 2010

\section{Keywords:}

Lentinus (Panus) tigrinus

Mycoremediation

Aromatic hydrocarbons

Historical contamination

Biodiversity

\begin{abstract}
A B S T R A C T
The ability of Lentinus tigrinus to grow and to degrade persistent aromatic hydrocarbons in aged contaminated soil was assessed in this study. L. tigrinus extensively colonized the soil; its degradation activity after $60 \mathrm{~d}$ incubation at $28^{\circ} \mathrm{C}$, however, was mostly limited to dichloroaniline isomers, polychlorinated benzenes and diphenyl ether while the fungus was unable to deplete 9,10-anthracenedione and 7-H-benz[DE]anthracene-7-one which were the major soil contaminants. Although clean-up levels were limited, both density of cultivable heterotrophic bacteria and richness of the resident bacterial community in L. tigrinus microcosms ( $L t \mathrm{M})$ increased over time to a significantly larger extent than the respective amended incubation controls $\left(1.9 \times 10^{9} \mathrm{CFU} \mathrm{g}^{-1}\right.$ vs. $1.0 \times 10^{9} \mathrm{CFU} \mathrm{g}^{-1}$ and 37 vs. 16 , respectively). Naphthalene- and catechol 2,3-dioxygenase gene copy numbers, however, decreased over time at a higher rate in $L t \mathrm{M}$ than in incubation controls likely due to a higher stimulation on heterotrophs than xenobiotics-degrading community members.
\end{abstract}

(C) 2010 Elsevier B.V. All rights reserved.

\section{Introduction}

The last decades have witnessed an increasing use of bioremediation approaches to the clean-up of soils contaminated by persistent organic pollutants (POP) as an alternative to physicochemical techniques [1,2]. The technical feasibility and the degradation efficiency of bioremediation depend on a large number of factors, such as type and bioavailability of contaminants, physico-chemical properties, history of the contaminated matrix, possible presence of co-contaminants [2,3]. The augmentation with ligninolytic fungi (LF) in ex situ bioremediation of POPcontaminated soils has been suggested to be more effective than in situ techniques under particular circumstances [1,3]. Such cases comprise sceneries where either low contaminant bioavailability or massive presence of compounds with low susceptibility to bacterial degradation or co-contamination with heavy metals negatively affect the degradation activity of both resident and allochthonous bacteria. Due to the structural heterogeneity of lignin, LF have evolved an extracellular degradation machinery that comprises lignin-modifying enzymes (LMEs) with low substrate specificity and operating via radical mechanisms. These peculiar properties

\footnotetext{
* Corresponding author at: Dipartimento di Agrobiologia \& Agrochimica, Università degli Studi della Tuscia, Via San Camillo de Lellis snc, I-01100 Viterbo, Italy. Tel.: +390 0761 357368; fax: +390 0761357242.

E-mail address: dannib@unitus.it (A. D’Annibale).
}

confer LF the ability to degrade a wide variety of contaminants [1]. LMEs are able to bring about both direct and mediator-assisted oxidation of target contaminants [4]. Moreover, filamentous fungi have the ability to penetrate into soil aggregates acting as dispersion vectors of pollutant-degrading bacteria [5] and exhibit a significant tolerance to heavy metals [6]. Although these organisms have been employed for remediation purposes, little information is so far available on the relationships between augmented LF and the indigenous microbiota and, with few exceptions [7,8], available data are mostly limited to artificially spiked soils $[9,10]$.

Among LF, Lentinus tigrinus has been shown to be able to degrade a variety of organic pollutants, such as polycyclic aromatic hydrocarbons [11,12], synthetic dyes [13], chlorinated phenols [14], 2,4,6-trinotrotoluene [15] and asphaltenes from hard coal [16]. These findings associated with its reported ability to produce significant amounts of LMEs on contaminated matrices [17] and to grow in the presence of heavy metals [18] suggest that it might be a promising species in bioremediation. So far, however, the impact of $L$. tigrinus augmentation on the resident microbiota has not been investigated.

Therefore, objectives of the present study were to assess (i) the ability of the L. tigrinus CBS 577.79 strain to clean-up a historically contaminated soil and to investigate (ii) time-dependent effect of fungal augmentation on the bacterial community structure and (iii) temporal variation of degradation genes of the resident bacterial community. Mycoaugmentation performances were tested on a contaminated soil from a decommissioned industrial site where 